\title{
Antitrypanosomal Effects of Crude Ethanolic Extract of Artemisia herba alba Follwing Experimental infection of Rabbits
}

\author{
${ }^{1 *}$ Fathy. M. A. Awad, ${ }^{2}$ Zainal Abidin Bin Abu Hasan, ${ }^{3}$ Abdinasir Yusuf Osman \\ and ${ }^{1}$ Nazlina Ibrahim \\ ${ }^{I}$ School of Biosciences and Biotechnology, Universiti Kebangsaan Malaysia, \\ 43600 UKM Bangi, Selangor, Malaysia. \\ ${ }^{2}$ Faculty of Medicine, Universiti Teknologi MARA UiTM, Shah Alam Selangor, Malaysia. \\ ${ }^{3}$ Faculty of Veterinary Medicine, Universiti Putra Malaysia, 43400 UPM Serdang, Selangor, Malaysia.
}

\begin{abstract}
There is potential growing interest in the context of exploring the medicinal effect of Artemisia spp in relation to parasitic diseases in many parties of the world. In this study, however, use of Artemisia herba alba as anti-parasitic source is exclusively new contribution to the currently available data base. The present work of the experimental nature was conducted to evaluate the antitrypanosomal efficacy of crude ethanolic extracts (CEE) of the aerial parts of Artemisia herba alba against Trypanosoma evansi infection in animal model. A total of thirty rabbits $(n=30)$ of approximately 5 - 6 months old, weighing $1.5-2.5 \mathrm{~kg}$ were divided into six main groups of five animals each. Animals in Groupl (pre-infection) were treated intraperitoneally (I.P) with $100 \mathrm{mg}$ $\mathrm{kg}^{-1}$ of CEE from two days before T. evansi infection until 4 days after infection. Group 2 (concurrent) was infected and concurrently treated with $100 \mathrm{mg} \mathrm{kg}^{-1}$ of CEE for 6 days. Group 3 (post-infection) was treated with $100 \mathrm{mg} \mathrm{kg}^{-1}$ of CEE 6 days after detection of parasitaemia. Group 4 (positive control) was treated intramuscular (I.M) with $3.5 \mathrm{mg} \mathrm{kg}^{-1}$ Berenil ${ }^{\circledR}$ (Diminazene aceturate) after establishment of parasitaemia following T. evansi infection. Group 5 (negative control) was infected with T. evansi only once with $1 \mathrm{ml}$ of $5 \times 10^{5}$ of T. evansi while group 6 serves as reference group and treated intraperitoneally with Alsever's solution. The results indicated significant difference $(p<0.05)$ in the context of reduction in the extent of clinical signs, low levels of parasitaemia and mortality pattern in animals received crude ethanolic extracts (CEE) of Artemisia herba alba compared to those served as negative group. Similarly, there was also haematologically significant difference $(p<0.05)$ where low mean levels of PCV was observed in the groups 1-4 respectively. In contrast, there was no statistically significant difference in almost all investigated parameters between standard group (positive control) and treatment group. In conclusion, both CEE of A. herba-alba and Berenil ${ }^{\circledR}$ showed relatively aparasitaemia and normal heamatologic values in the infected rabbits, thereby confirming their antiparasitic properties.
\end{abstract}

\section{Introduction}

Trypanosomiasis is disease caused by a variety of species of haemoprotozoan parasites which are cyclically transmitted by tsetse flies of the genus: Glossina throughout 10 million $\mathrm{km}^{2}$ of the African landmass (Barrett et al., 2003). Both almost all animal species, except poultry, and human are equally affected. Information, however, relating to the species of the trypanosomes and type of the vectors that are responsible for transmission dynamics of trypanosomes have been extensively published in documents and database aimed at scientific community in a wide range of multi disciplines including medicine, veterinary science as well as ecology. However, Trypanosoma evansi is the subject of this paper; a pathogenic flagellated protozoan parasite affecting domestic livestock and wildlife with great influence on animal production. It has been globally reported across different geographical regions in Asia, Africa and Latin America (Luckins and Dwinger, 2004). Buffalo, cattle, camels and horses are particularly prone to the disease caused by specifically this haemoprotozoan, although other animals, including wildlife, can also be infected (OIE, 2008).

The current methods of controlling trypanosomiasis with respect to the livestock include the use of trypanotolerant cattle, vector control and drug therapy. The chemotherapy choice might no longer remain due to problems ranged from availability in the market to the toxicity in the host. Thus, use of medicinal plants as an alternative targets for future development therapeutic drugs has recently come the focus of many researchers in developing countries. In line with this, the Libyan medicinal plant; Artemisia herba alba Asso $=[$ Artemisia aragonensis Lam., Seriphidium herba alba (Asso) Soja'k] (Greuter, 2006-2009), commonly known as white wormwood or desert wormwood (Arabic name Chih), has been used. The plant is a greyish-strongly aromatic dwarf shrub native to the South Western Europe, Northern Africa, including Libya, Arabian Peninsula and Western Asia. A recent review detailed the distribution, taxonomy, morphology, phytochemistry and biological activities of $A$. herba-alba and its different extracts (Mohamed et al., 2010). The variability from the essential 
oils isolated from $A$. herba-alba collected at different geographical regions was revised by Dob and Benabdelkader in 2006. The aim of the present study was to determine the trypanocidal efficacy of $A$. herba alba in rabbits induced experimentally with $T$. evansi in comparison to that of commercially available trpanposomal drug Berenil®.

\section{Plant Material and the Extract Preparation}

\section{Materials And Methods}

A. herba-alba was collected from the Eastern part of Libya (Green mountain area) and identified by a botanist at the Botany Department, Omar Al Mukhtar University, Al Beida, Libya. The aerial part of the plant material was air dried and the crude ethanolic extract (CEE) was prepared at the Faculty of Science and Technology, Universiti Kebangsaan Malaysia (UKM) Bangi. Dried plants of $A$. herba alba were grounded into powder. Five hundred gram powdered plant material was extracted in a Soxhlet apparatus with $95 \%$ ethanol at a temperature of $50^{\circ} \mathrm{C}$ for 12 hour (h). The residue was removed by filtration. CEE was concentrated in a rotary evaporator under reduced pressure at temperature of $40-50{ }^{\circ} \mathrm{C}$ and then lyophilized to obtain a powdered CEE and stored at $4^{\circ} \mathrm{C}$ until used (Ene et al, 2009).

\section{Animals}

Thirty ( $\mathrm{n}=30$ ) male New Zealand clinically healthy rabbits of approximately $5-6$ months old, and weighing $1.5-2.5 \mathrm{~kg}$ were used in this study. Upon arrival all rabbits were screened for the presence of haemoprotozoan parasites using wet mount and leishman stained blood films and were all confirmed negative. The animals were placed in large appropriate metal cages (1 per cage) and maintained in a fly proof isolation unit at the experimental animal house, Faculty of Biosciences and Biotechnology, Universiti Kebangsaan Malaysia (UKM). Their diet consisted of chaw pellets, fresh vegetables and allowed tap water ad libitum. Prior the experiment, all animals were for 2-3 weeks for acclimatization period. All procedures and experiments described were undertaken under a project license approved by the Ethics committee of UKM (UKMAEC).

\section{Stock of Parasites and Inoculation}

The Trypanosoma evansi isolate used in this experiment was obtained from the Parasitology Laboratory, Faculty of Veterinary, Universiti Putra Malaysia (UPM). The parasite was originally isolated from a naturally infected deer from Perak state, Malaysia in 2007 (Adrian et al, 2010). A cryopreserved clone was subpassaged preserved into ICR mice to allow trypanosome multiplication. These animals were then exsanguinated after they had developed a fulminating parasitaemia. An inoculum of $5 \times 10^{5}$ parasites in $1 \mathrm{ml}$ was then prepared by diluting the pooled mice blood with Alsever's solution. Five rabbits of each group were infected intraperitoneally (I.P) with $1 \mathrm{ml}$ of the prepared inoculums.

\section{Experimental procedure}

At the start of the experiment, the rabbits were randomly divided into 6 major groups of 5 rabbits in each group (Table 1). Animals of Group 1 were pre-treated for two days intraperitoneally with $100 \mathrm{mg} \mathrm{kg}^{-1}$ of crude ethanolic extract (CEE) of the aerial parts of $A$. herba alba before inoculation with $T$. evansi and thereafter treated for 6 days after infection. Rabbits of Group 2 were treated intraperitoneally with $100 \mathrm{mg} \mathrm{\textrm {kg } ^ { - 1 }}$ of CEE of $A$. herba alba and concurrently infected with T. evansi. Rabbits of Group 3 were treated 6 days with $100 \mathrm{mg} \mathrm{kg}^{-1}$ of CEE of $A$. herba alba for 6 days after establishment of parasitaemia. Animals in Group 4 were

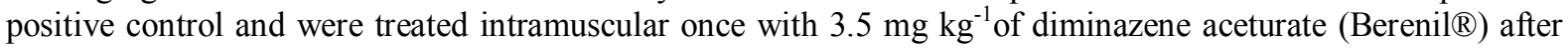
the establishment of parasitaemia. Rabbits in Group 5 were only infected once intraperitoneally with $1 \mathrm{ml}$ of $5 \times 10^{5}$ parasites. Animals of Group 6 served as reference group and were injected intraperitoneally with $1 \mathrm{ml}$ of sterile Alsever's solution. The detailed information of the experimental design was summarized in Table 1.

\section{Parasitemia estimation}

All the animals were sampled at two days interval during 48 days post infection (pi), about $2 \mathrm{ml}$ of peripheral blood were collected from the rabbit's marginal ear vein after shaving the area. Parasitaemia count was determined by Micro- Haematocrit Centrifugation Technique (MHCT) (Woo, 1970). About $75 \mu 1$ of fresh blood were taken with a heparinized capillary and centrifuged for $5 \mathrm{~min}$ at $12,000 \mathrm{~g}$. Capillary tubes were examined using a light microscope (100 or $400 \mathrm{X}$ magnification) for detection and counting trypanosomes when the numbers were few around the buffy coat plasma interphase area (Woo, 1970). High parasitaemia enumeration was undertaken using a Neubauer hemocytometer. 
Table 1: Experimental design

\begin{tabular}{|c|c|c|c|c|c|c|}
\hline Group & Category & Description & $\begin{array}{c}\text { No. of } \\
\text { animals }\end{array}$ & $\begin{array}{l}\text { Dose of CEE } \\
\left(\mathrm{mg} \mathrm{kg}^{-1}\right)\end{array}$ & $\begin{array}{c}\text { Volume of } \\
\text { inoculum of } T \text {. } \\
\text { evansi }(\mathrm{ml})\end{array}$ & $\begin{array}{c}\text { Route of } \\
\text { administration }\end{array}$ \\
\hline 1 & Pre-infection & $\begin{array}{l}\text { Pre-treated with CEE of } A \text {. } \\
\text { herba alba before } 2 \text { days of } \\
\text { T. evansi infection }\end{array}$ & 5 & 100 & $1 \mathrm{ml}$ of $5 \times 10^{5}$ & $\mathrm{I} / \mathrm{p}$ \\
\hline 2 & Concurrent & $\begin{array}{l}\text { Treated with CEE of } A \text {. } \\
\text { herba alba concurrently } \\
\text { infected with } T \text {. evansi }\end{array}$ & 5 & 100 & $1 \mathrm{ml}$ of $5 \times 10^{5}$ & $\mathrm{I} / \mathrm{p}$ \\
\hline 3 & Post-infection & $\begin{array}{l}\text { Treated once after } \\
\text { establishment of } \\
\text { parasitaemia. }\end{array}$ & 5 & 100 & $1 \mathrm{ml}$ of $5 \times 10^{5}$ & $\mathrm{I} / \mathrm{p}$ \\
\hline 4 & $\begin{array}{l}\text { Positive } \\
\text { control }\end{array}$ & $\begin{array}{l}\text { Treated with diminazene } \\
\text { aceturate after establishment } \\
\text { of parasitaemia. }\end{array}$ & 5 & 3.5 & $1 \mathrm{ml}$ of $5 \times 10^{5}$ & $\mathrm{I} / \mathrm{m}$ \\
\hline 5 & $\begin{array}{l}\text { Negative } \\
\text { Control }\end{array}$ & $\begin{array}{l}\text { Infected with } T \text {. evansi and } \\
\text { remain untreated }\end{array}$ & 5 & $* \mathrm{~N} / \mathrm{A}$ & $1 \mathrm{ml}$ of $5 \times 10^{5}$ & $\mathrm{I} / \mathrm{p}$ \\
\hline 6 & Reference & $\begin{array}{l}\text { Uninfected but treated with } \\
\text { Alsever's solution. }\end{array}$ & 5 & $* \mathrm{~N} / \mathrm{A}$ & $* \mathrm{~N} / \mathrm{A}$ & $\mathrm{I} / \mathrm{p}$ \\
\hline
\end{tabular}

N/A: Not applicable

\section{Collection of blood samples}

Blood samples were obtained once every two weeks by rabbit's marginal ear vein after shaving the area from day of infection to 48 days post-infection (DPI). Blood samples for hematology were collected into tubes containing ethylenediaminetetraacetic acid (EDTA) as the anticoagulant.

\section{Clinical examination}

Animals were closely observed daily for clinical signs that included loss of condition, oedema of the face, ocular discharges, encrustation of the lips, lethargy and mortality rate.

\section{Hematology}

The packed cell volume (PCV) was measured using micro-haematocrit technique. The total red blood cell count (RBC), total white blood cell count (WBC) and hemoglobin ( $\mathrm{Hb}$ ) concentration were conducted using the Cell-Dyn 3700 Automatic Analyzer (Vet Package, Abbot Diagnostic, 2007) conducted at the Hematology and Biochemistry Laboratory, Faculty of veterinary medicine, Universiti Putra Malaysia (UPM). Red cell indices such as the mean corpuscular volume (MCV) and mean corpuscular haemoglobin concentration (MCHC) were calculated from the results obtained from RBC, $\mathrm{Hb}$ and PCV according to Wintrobe (1942). The differential leukocyte count was performed on blood smears stained with a mixture of May- Gruenwald, Giemsa, and methanol.

\section{Statistical methods}

The statistical package Version JMP 9, SAS was used for statistical analysis. The mean values obtained from hemograms from infected animals were compared with data from the control group using the Tukey-test. Differences were considered to be statistically significant with values of $P<0.05$.

\section{Parasitemia}

\section{Results}

In general, parasites (T. evansi) were not detected in the blood samples of all groups 1-5 of infected intraperitoneally with $T$. evansi between Day 1 to Day 2 post-infection. However, parasitaemia peaks were observed after 3 days post-infection (DPI) in all experimentally challenged rabbits. Maximum parasitaemia on the $6^{\text {th }}-8^{\text {th }}$ days pos-infection (DPI) with all 5 animals in each group being positive for $T$. evansi. After 10 days post-infection, periods of low parasitaemia were intermixed with parasitaemia periods in rabbits of experimental groups 1-4 (Fig. 1.). Thereafter, aparasitaemic levels was observed at day 11 which maintained until the end of the experimental period with the all animals in each group (1-4) being negative for $T$. evansi. In contrast, animals in group 5 (negative control), parasitaemia was recorded from day 3 post-infection where animals remained with the high peaks of parasitaemia between day 10-35 post-infection (Fig. 2) . The reference group remained aparasitemic for the duration of the whole experimental period (Fig. 1.). 


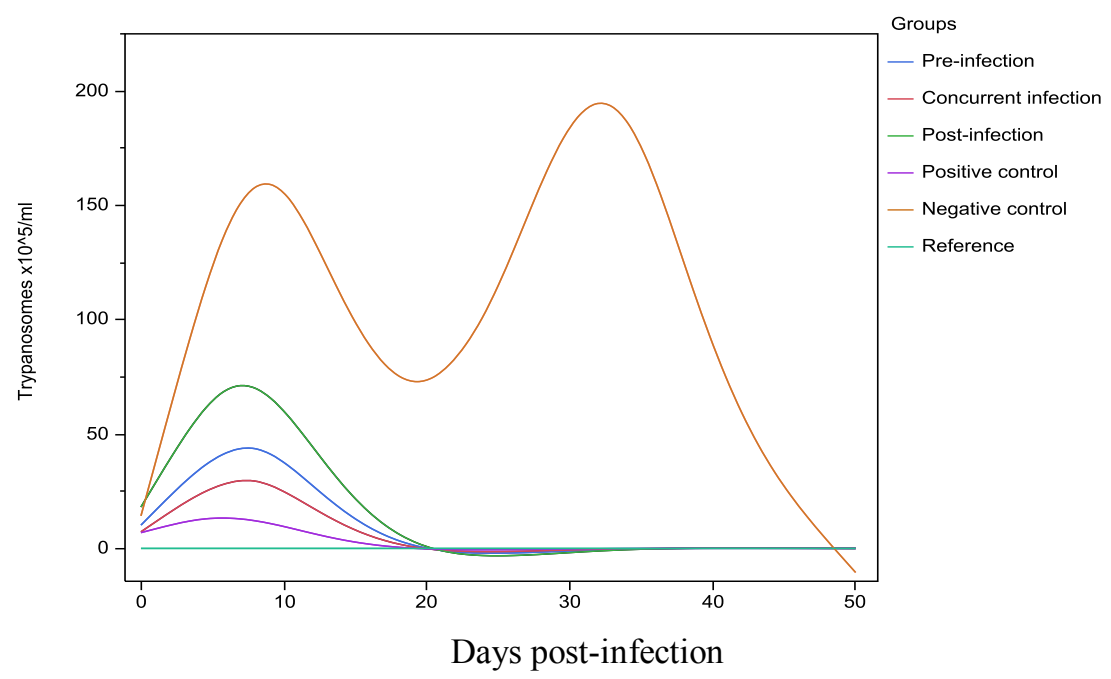

Fig.1 Parasitemia of T. evansi from groups (1-6) involved in the study

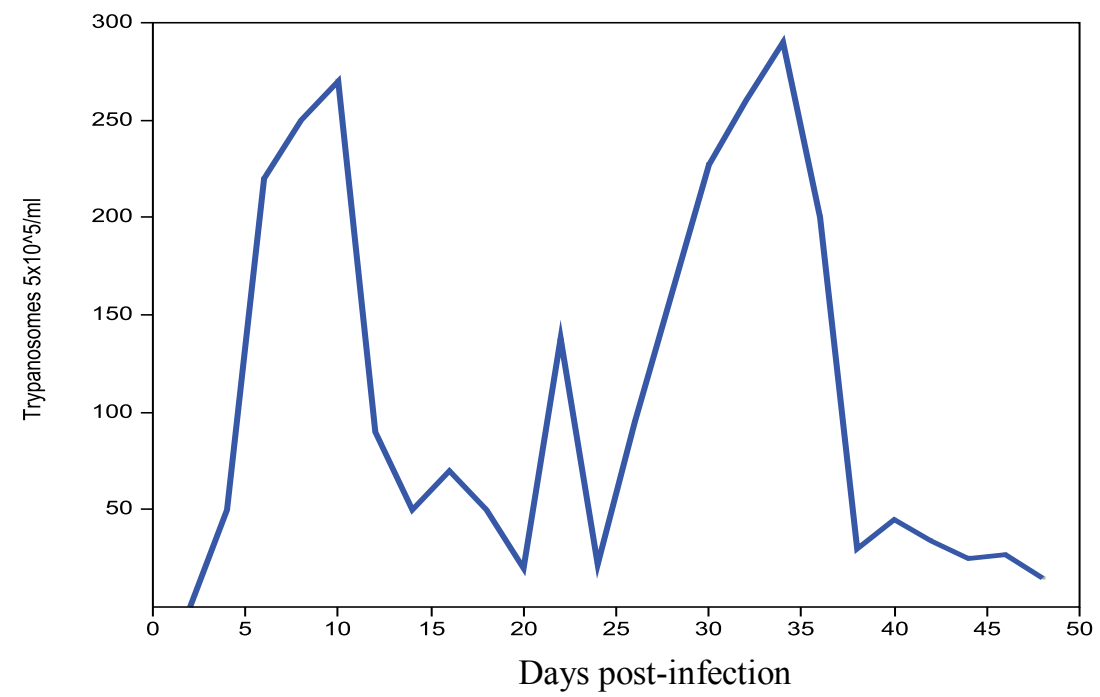

Fig.2. Parasitemia of T. evansi from groups challenged only with Trypanosomes study.

\section{Clinical Observation}

Animals served as negative control were severely affected after experimental infection with T. evansi. In these animals, the clinical signs due to the infection of T.evansi appeared on day 3 post-infection where most of the animals exhibited typical clinical signs that included oedema in the face, ocular discharges, poor condition and encrustation of the lips. The mean rank of these tested parameters was significantly higher than all treated groups and control group (Fig. 3-6). In contrast, these clinical signs were prevented by intraperitoneal administration of $A$. herba alba alba in groups 1-3 throughout the experimental period. Similarly, animals treated with the standard drug (Berenil $\left.{ }^{\circledR}\right)$ showed no clinical signs for the whole duration of the experimental period (Fig.3-6). No significant difference was observed between CEE treated and Berenil@ treated group (Fig.3-6). 


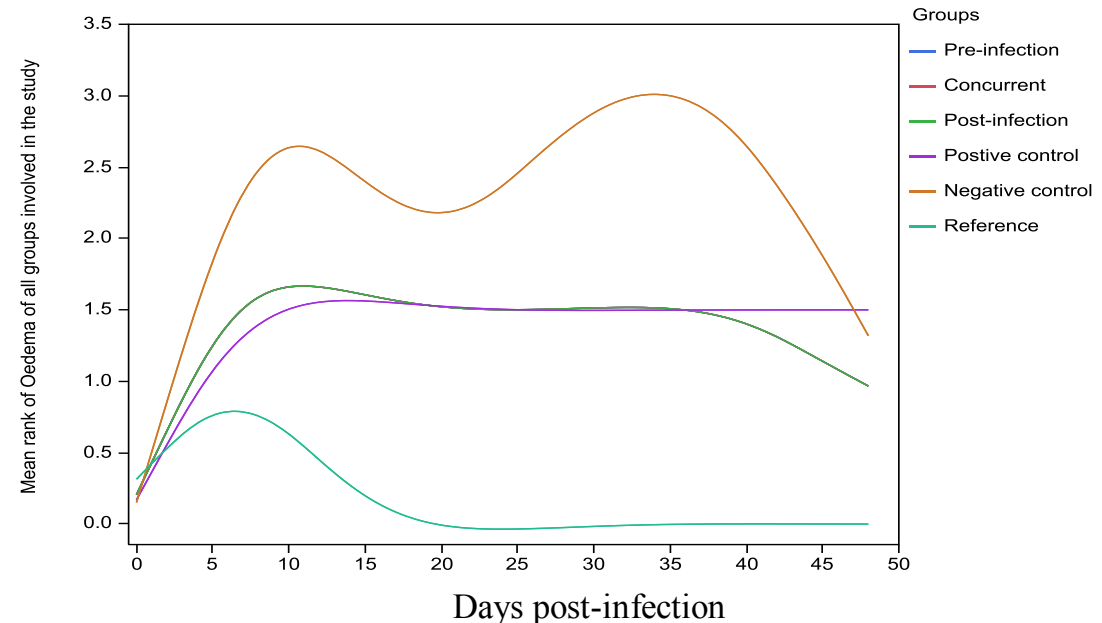

Fig. 3. Mean rank of the Oedema of all groups involved in the study.

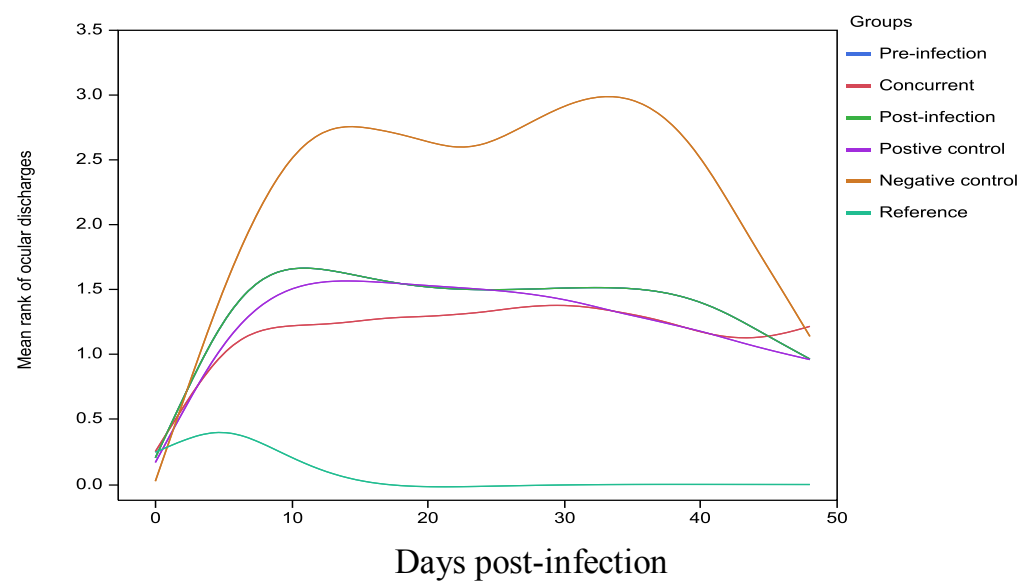

Fig. 4. Mean rank of ocular discharge of all groups involved in the study.

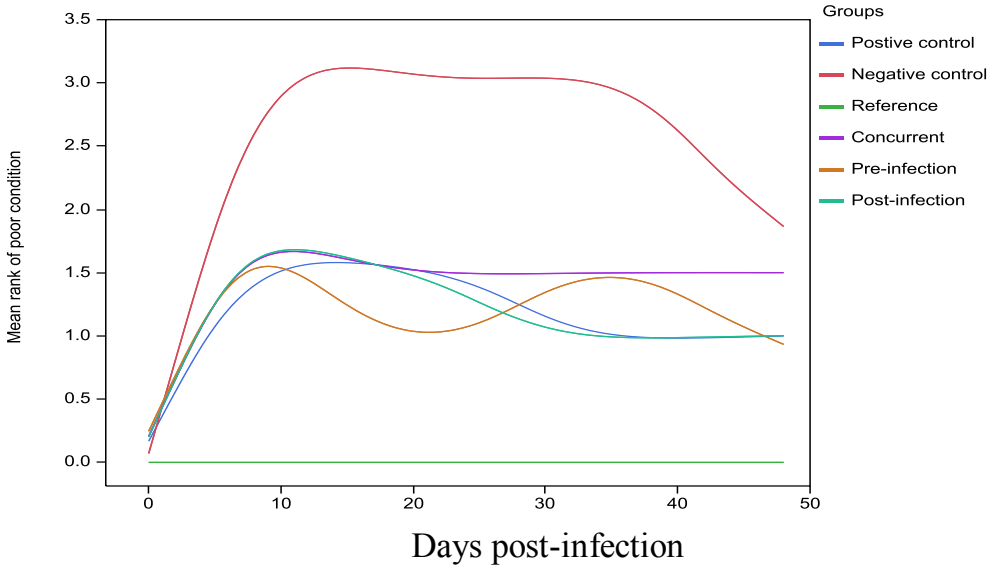

Fig. 5. Mean rank of poor condition of all groups involved in the study. 


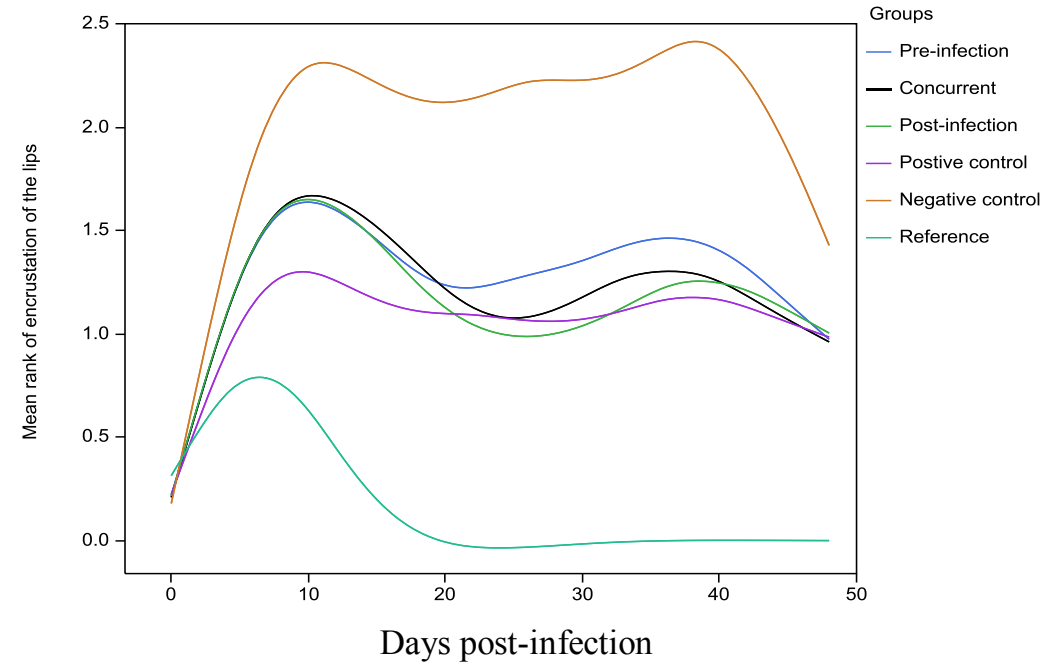

Fig. 6. Mean rank of poor condition of all groups involved in the study.

\section{Hematological changes}

The mean values of blood indices are summarized in Fig 7-10. Animals in group 5 (negative control) showed statistically a significant decrease in values of RBC, PCV, and $\mathrm{Hb}$ following infection intraperitoneally with $1 \mathrm{ml}$ of $5 \times 10^{5}$ of parasites. The values of these parameters dropped from the first week and remained lower than the values found in both control and treated animals until the end of the experimental period. In contrast, the PCV, RBC and $\mathrm{Hb}$ values of treated groups (1-4) showed slight decrease in serum levels between day $3-5$ post-infection. Thereafter, normalization of these values (PCV, RBC \& $\mathrm{Hb}$ ) was observed and remained unchanged throughout the experimental period (Fig. 4).

Animals served as reference group, the serum concentration of all tested parameters remained unchanged until the end of the experimental period.

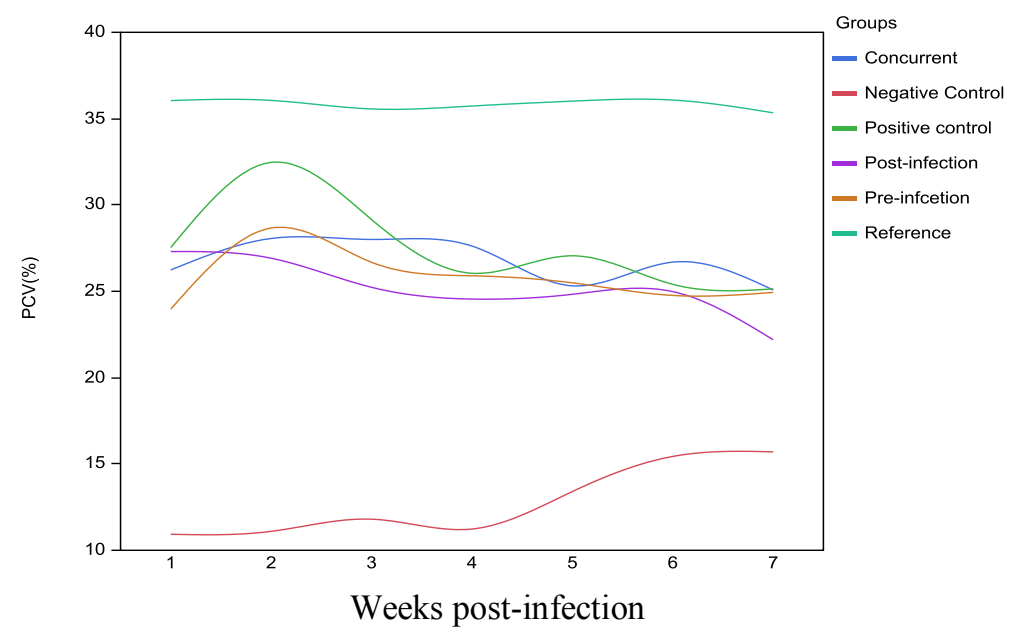

Fig. 7. Mean rank of PCV(\%) of all groups involved in the study. 


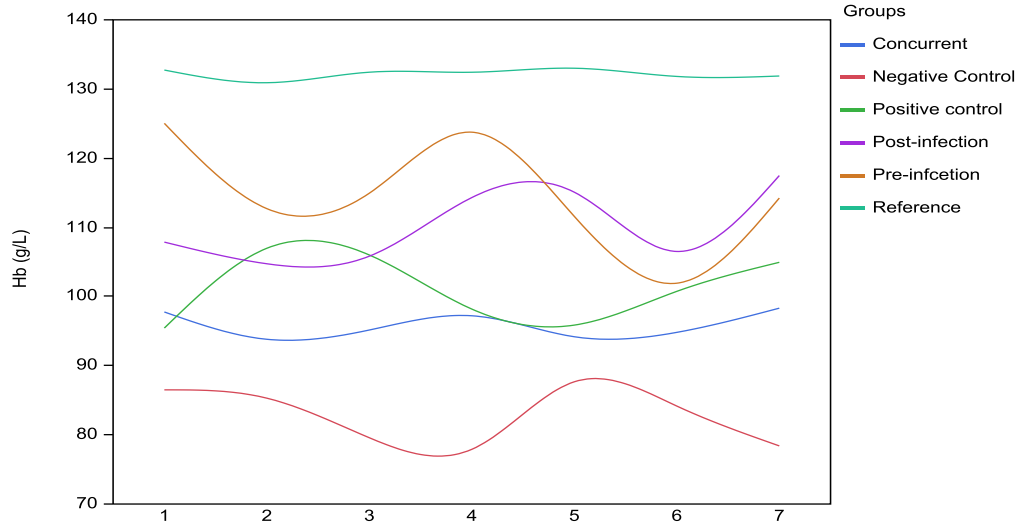

Weeks post-infection

Fig. 8. Mean rank of $\mathrm{Hb}(\mathrm{g} / \mathrm{L})$ of all groups involved in the study.

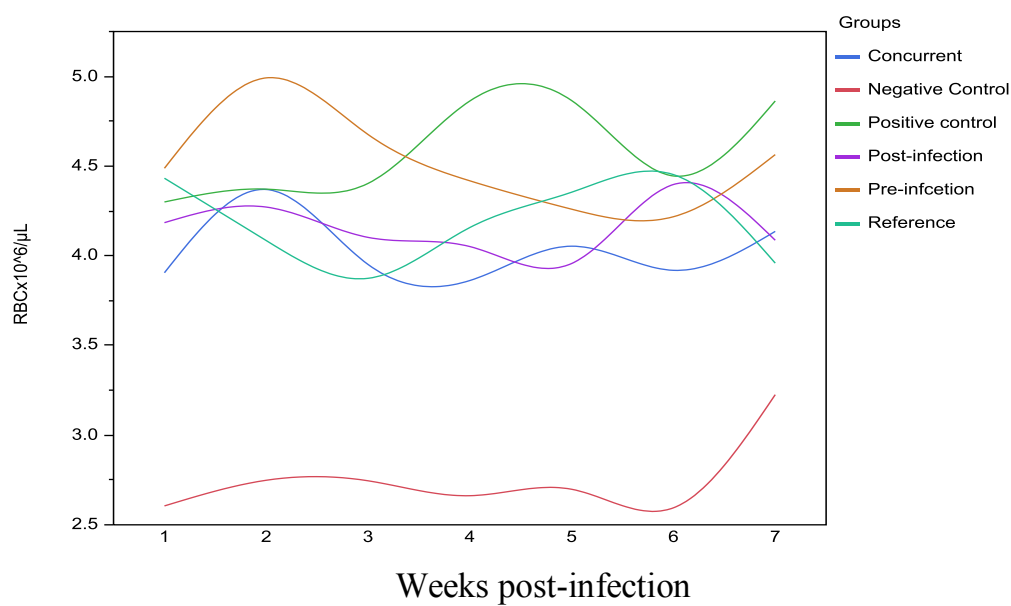

Fig. 9. Mean rank of RBC ( $\mu / \mathrm{L})$ of all groups involved in the study.

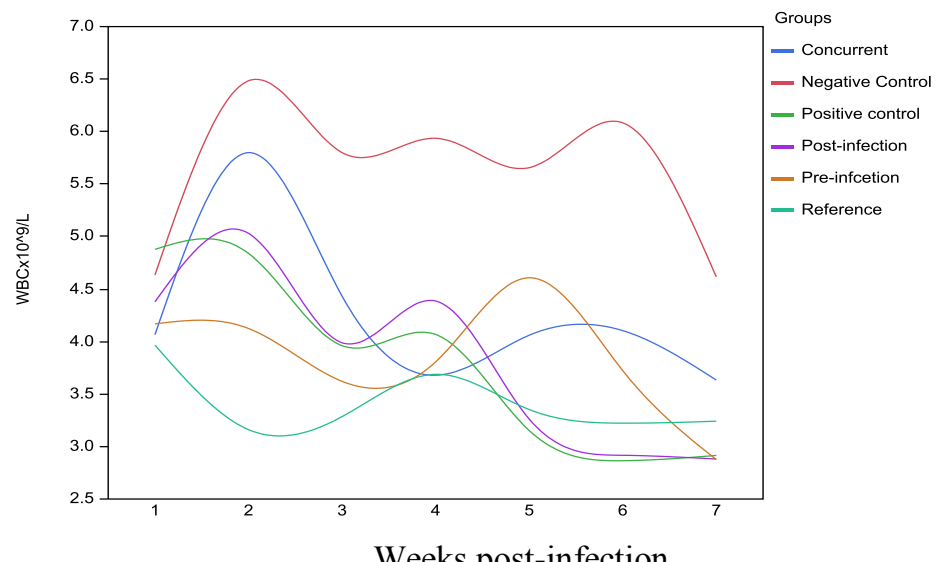

Fig. 10. Mean rank of WBC of all groups involved in the study. 


\section{Discussion}

Animals were closely observed daily for clinical signs that included loss of condition, oedema of the face, ocular discharges, encrustation of the lips and mortality rate. The present work of the experimental nature had indicated that manipulation of $T$. evansi led to the production of parasitaemia in certain stages in all groups of 1-5 that involved in the study. Within the first 3 days post infection, the levels of the parasitaemia were significantly $(\mathrm{p}<0.05)$ associated with gradual loss of condition, facial oedema and ocular discharges in almost all involved groups (1-5). These clinical signs are in agreement with those reported earlier in other studies of experimental nature (Losos and Ikede, 1972). In the negative group, however, the course of trypanosomiasis due to $T$. evansi can be summarized into two main stages. The early stage is characterized by high levels of parasitaemia along with the rapid development of anemia. This was in agreement to Aquino et al. (1999) in dogs. In the later stage of the infection, the rabbits developed a persistent and severe anemia while only a few parasites could be detected in the blood. This is explained by the chronic nature of the infection in these animals.

The present work had indicated that when the condition is treated with crude ethanolic extract of $A$. herba alba, at the dose used, caused an initial and transient parasitaemia suggesting the antiparasitic properties

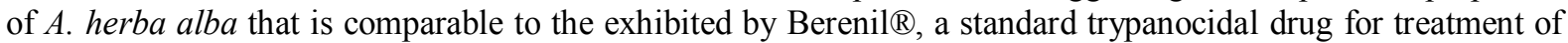
trypanosomosis in animals. Relapse of the infection however occurred in all treatment individuals. Literature has supported that this phenomenon (relapse infection) might even occur with the most conventional trypanocidal drugs (Onyeyili and Anika, 1990). A possible explanation for this is the presence of the parasites in drug inaccessible sites such as the brain (Onyeyili and Anika, 1990).

The present results indicate that the extract of $A$. herba alba possessed no significant differences when tested pre, concurrent or post infection. Thus, there was no significant difference among animals treated with crude ethanolic extract of $A$. herba alba in terms of haematological values. There were no significant differences in certain parameters such as total protein, bilirubin, and plasma glucose mean values between infected and treated rabbits (data excluded). These findings are at variance with those reported by Twaij and A1-Badr (1988), who reported hyboglycaemic effect of $A$. herba alba normoglycaemic and alloxan-diabetic rabbits and Husnia et al. 1995, who conversely reported hyperglycaemic effect of $A$. herba alba in white New Zealand rabbits . The reason for this discrepancy is not known. However, in our experiment is differed from their studies by manipulation of $T$. evansi in treated animals. Moreover, in our study, the fact that the animals were given abundant food may have influenced glucose levels and may not reflect the actual serum concentration of this parameter. It would be of interest to investigate these parameters in subjects without impaired infection of $T$. evansi but treated with $A$. herba alba.

\section{Conclusion}

This study demonstrated the curative properties of $A$. herba alba alba by producing aparasitaemic effect, reducing associated clinical signs of $T$. evansi and preventing haematological alterations in the treated groups.

\section{Acknowledgments}

The authors are grateful to Prof. Dr. Shukor Mohd Nor for his valuable assistance. Also, an appreciation to all personnel at the animal house (Rumah Haiwan) of UKM Bangi for their help. The first author would like to thank the Libyan Ministry of High Education for Financial Support.

\section{Conflict of interest}

The authors declare that they have no conflict of interest with the contents of this paper in any respect

\section{References}

[1]. Adrian, M. S., Sani, R. A., Hassan, L. \& Wong., M. T. 2010. Outbreaks of trypanosomiasis and the seroprevalence of T. evansi in a deer breeding centre in Perak, Malaysia. Tropical Animal Health and Production. 42: 145-150.

[2]. Aquino, L.P.C.T., Machado, R.Z., Alessi, A.C., Marques, L.C., Castro, M.B., Malheiros, E.B., 1999. Clinical, parasitological and immunological aspects of experimental infection with Trypanosoma e ansi in dogs. Mem. Inst. Oswaldo Cruz 94, $255-260$.

[3]. Barrett, M.P., Burchmore, R.J.S., Stitch, A., Lassan, J.O., Frasch, A.C., Cazzulo, J., Krishna, S., 2003. The trypanosomiases. Lancet 362 (9394), 1469-1480.

[4]. Dob, T., Benabdelkader, T., 2006. Chemical composition of the essential oil of Artemisia herba-alba Asso grown in Algeria. J. Essent. Oil Res. 18, 685-690.

[5]. Ene, A.C., Atawodi, S.E., Ameh, D.A., Nnamani, C.N. \& Apeh, Y.E.O. 2009. Antitrypanosomal effects of petroleum ether, chloroform and methanol extracts of Artemisia maciverae Linn. Indian Journal of Experimental Biology. 47: 981-986.

[6]. Greuter, W. (2006-2009): Compositae (pro parte majore). In: Greuter, W. \&Raab-Straube, E. von (ed.): Compositae. Euro+Med Plantbase - the information resource for Euro-Mediterranean plant diversity. http://ww2.bgbm.org/EuroPlusMed/ [accessed 07.11].

[7]. Losos,G.J. and Ikede,B.O., 1972. Review of Pathology of disease in domestic and Laboratory animals caused by Trypanosoma congolense. 
[8]. Luckins, A.G. \& Dwinger, R.H. 2004. Non-tsetse-transmitted animal Trypanosomiasis. In: Maudlin, Holmes, P.H., Miles, M.A. (Eds), The Trypanosomiases. Cabi Publishing, Trowbidge. 269-281 pp.

[9]. Mohamed, N.S., 2010. Chemical constituents and biological activities of Artemisia herba-alba. Records of Natural Products 4, 1-25.

[10]. OIE. 2008. Manual of Diagnostic Tests and Vaccines for Terrestrial Animals www.oie.int.

[11]. Onyeyili, P.A. and Anika,S.M, 1990. Effect of the combination of DL and D Difluoromethyl Ornithine and diminazene aceturate in Trypanosoma congolense infection in dogs. Veterinary chemotherapy of African Trypanosomisasis: A historical perspective. Vol.19.No.5.

[12]. Twaij, H.A.A and Al-Badr, A. 1988,.Hypoglycaemic activity of Artemisia herba alba. Journal of Ethnopharmacology, 24, $123-126$.

[13]. Woo, P.T.K. 1970. The haematocrit centrifuge technique for the diagnosis of African Trypanosomiasis. Acta Tropica. 27: $384-386$. 